\title{
Effect of red blood cell transfusion on short-term outcomes in very low birth weight infants
}

\author{
Eui Young Lee, MD, Sung Shin Kim, MD, PhD, Ga Young Park, MD, PhD, Sun Hyang Lee, MD \\ Department of Pediatrics, Soonchunhyang University Bucheon Hospital, Soonchunhyang University College of Medicine, Bucheon, Korea
}

Background: Red blood cell (RBC) transfusion improves cardiorespiratory status of preterm infants by increasing circulating hemoglobin, improving tissue oxygenation, and reducing cardiac output. However, RBC transfusion itself has also been suggested to negatively affect short-term outcomes such as intraventricular hemorrhage (IVH), bronchopulmonary dysplasia (BPD), retinopathy of prematurity (ROP), and necrotizing enterocolitis (NEC) in premature infants.

Purpose: This study aimed to analyze the relationship between RBC transfusion and short-term outcomes in very low birth weight (VLBW) infants (birth weight, $<1,500 \mathrm{~g}$ ).

Methods: We retrospectively reviewed the medical records of VLBW infants admitted to the Soonchunhyang University Bucheon Hospital between October 2010 and December 2017. Infants who died during hospitalization were excluded. The infants were divided into 2 groups according to RBC transfusion status. We investigated the relationship between RBC transfusion and short-term outcomes including BPD, ROP, NEC, and IVH.

Results: Of the 250 enrolled VLBW infants, 109 (43.6\%) underwent transfusion. Univariate analysis revealed that all shortterm outcomes except early-onset sepsis and patent ductus arteriosus were associated with $\mathrm{RBC}$ transfusion. In multivariate analysis adjusted for gestational age, birth weight and Apgar score at 1 minute, $\mathrm{RBC}$ transfusion was significantly correlated with BPD (odds ratio [OR], 5.42; $P<0.001)$ and NEC (OR, $3.40 ; P=0.009)$.

Conclusion: $\mathrm{RBC}$ transfusion is significantly associated with adverse clinical outcomes such as NEC and BPD in VLBW infants. Careful consideration of the patient's clinical condition and appropriate guidelines is required before administration of RBC transfusions.

Key words: Erythrocyte transfusion, Very low birth weight infant, Bronchopulmonary dysplasia, Necrotizing enterocolitis, Premature infant

\section{Key message}

Question: Does RBC transfusion affect the short-term outcomes of VLBW infants?

Finding: The results showed that $\mathrm{RBC}$ transfusion was significantly related to the incidence of $\mathrm{BPD}(\mathrm{OR}, 5.42 ; P<0.001)$ and NEC (OR, 3.40; $P=0.009)$.

Meaning: Careful consideration of the patient's clinical condition and appropriate guidelines is required before administering RBC transfusions.

\section{Introduction}

The development of neonatal intensive care has improved the survival of low birth weight and premature infants compared to previous years. In Republic of Korea, survival rates of very low birth weight (VLBW) infants (birth weight, $<1,500 \mathrm{~g}$ ) and extremely low birth weight (ELBW) infants (birth weight, $<1,000 \mathrm{~g}$ ) were $35.6 \%$ and $6.5 \%$ respectively in the 1960 s. However, in the early part of 2010 , these rates increased to 85.3\% (VLBW) and 68.9\% (ELBW). ${ }^{1)}$

As the survival rate of low birth weight infants increases, the need for red blood cell (RBC) transfusions has also increased. Especially in the early postnatal period, low birth weight infants are at high risk for cardiopulmonary dysfunction and undergo many laboratory tests. Frequent phlebotomy leads to anemia and RBC transfusion in low birth weight infants. ${ }^{2)}$ The smaller the body weight, the greater the need for RBC transfusion. More than two-thirds of RBC transfusions in VLBW infants are administered in the first month of life. ${ }^{3)}$

$\mathrm{RBC}$ transfusion is known to improve cardiorespiratory status by increasing circulating hemoglobin $(\mathrm{Hb})$ and improving tissue oxygenation in preterm infants. However, in some studies, it has been reported that RBC transfusion increases the incidence of significant short-term adverse outcomes such as intraventricular hemorrhage (IVH), bronchopulmonary dysplasia (BPD), retinopathy of prematurity (ROP), and necrotizing enterocolitis (NEC). ${ }^{4-7)}$

\footnotetext{
Corresponding author: Sung Shin Kim, MD, PhD. Department of Pediatrics, Soonchunhyang University Bucheon Hospital, Soonchunhyang University College of Medicine, 170 Jomaru-ro, Bucheon 14584, Korea 


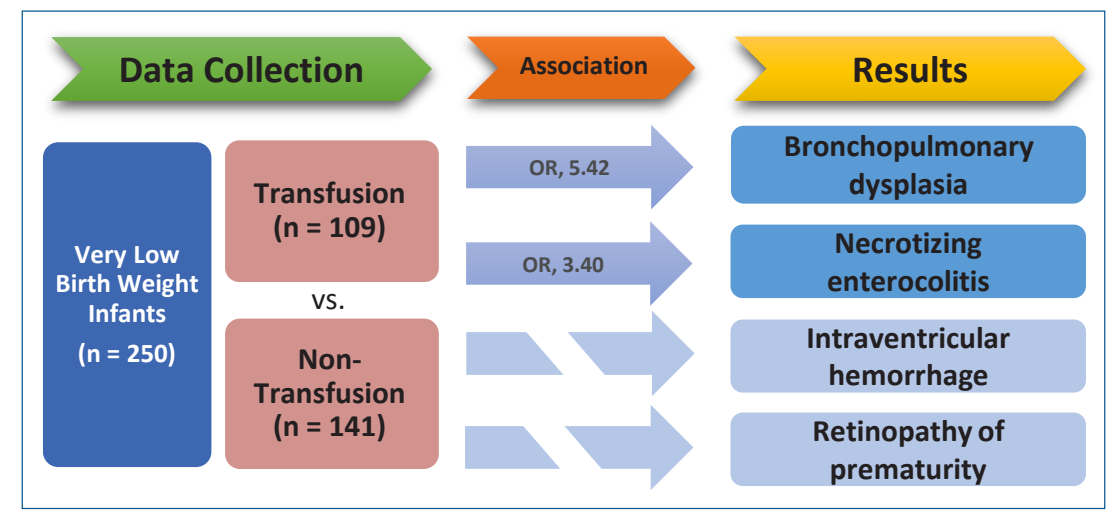

Graphical abstract. Is red blood cell transfusion significantly associated with the short-term outcomes of very low birth weight infants?

Baer et al. ${ }^{8)}$ reported that RBC transfusion in VLBW infants is an independent risk factor for severe IVH. Other studies have suggested that plasma nontransferrin bound iron is significantly increased in premature infants after RBC transfusion, and oxidative injury resulting from the production of oxygen-derived free radicals contributes to developing BPD and ROP. ${ }^{9}{ }^{10)}$ It has been suggested that RBC transfusion increases the incidence of NEC by alteration of mesenteric artery blood flow. ${ }^{6,11,12)}$

To our knowledge, there have been few reports that analyzed the correlation between RBC transfusion and various diseases in Republic of Korea. In the present study, we analyzed the correlation between RBC transfusion and short-term outcomes including IVH, BPD, ROP, NEC, PDA, sepsis in VLBW infants admitted to the neonatal intensive care unit (NICU) in Korea.

\section{Methods}

\section{Patients and methods}

This study conformed to the ethical guidelines of the 1975 Declaration of Helsinki and was approved by the Institutional Review Board (IRB) of the Soonchunhyang University Bucheon Hospital (IRB No. 2018-10-013).

We retrospectively reviewed medical records of 312 VLBW infants who had been admitted to Soonchunhyang University Bucheon Hospital between October 2010 and December 2017.

Infants who died during the hospitalization $(n=37)$ were excluded. The majority of these infants $(n=26)$ died within 7 days (extreme immaturity infants, $n=10$; pneumothorax, $n=5$; pulmonary hemorrhage, $\mathrm{n}=2$; IVH, $\mathrm{n}=4$; hypoxic damage, $\mathrm{n}=3$; sepsis, $\mathrm{n}=1$; heart failure, $\mathrm{n}=1$ ). $\mathrm{RBC}$ transfusion was performed as a life-saving treatment in 4 of these infants. The remaining 11 deaths occurred more than one week after birth. Among them, 2 infants were diagnosed with NEC at 6 and 11 days after RBC transfusion. One infant died of BPD after 3 RBC transfusions. Three of the infants died after one month of age (BPD, $\mathrm{n}=2$; sepsis, $\mathrm{n}=1$ ).

Out of the 275 surviving patients, infants who were transferred to another hospital were excluded $(n=24)$. Because there was no pediatric surgeon in our hospital, most of these transfers were for surgery, including NEC $(n=20)$, patent ductus arteriosus (PDA) $(n=1)$, tracheoesophageal fistula $(n=1)$, choledochal cyst $(n=1)$, and evaluation of citrullinemia $(n=1)$. One patient was excluded because maternal history and Apgar scores were missing from the records.

A flowchart illustrating the course of the study is presented in Fig. 1.

Finally, 250 patients were enrolled in the study. These patients were divided into 2 groups according to their $\mathrm{RBC}$ transfusion status. The decision for RBC transfusion was made by the neonatologist based on clinical judgment and transfusion guidelines based on the "Manual of Neonatal Care" published in the Korean Society of Neonatology and Fanaroff and Martin's Neonatal-Perinatal Medicine. ${ }^{13,14)}$ Packed RBCs were transfused in a dose of 10 to $15 \mathrm{~mL} / \mathrm{kg}$ over 3 to 4 hours. Packed RBC units were filtered and irradiated. Feeding was skipped before and after RBC transfusion. Aliquot RBC was not used. In the study period, erythropoietin (EPO) was not routinely administered in our hospital. Blood sampling was collected in microcollection tube and blood gas analysis in capillary tube. Umbilical cord milking and delayed cord clamping were rarely performed due to uncooperative obstetrics.

We evaluated various perinatal and postnatal variables, includ-

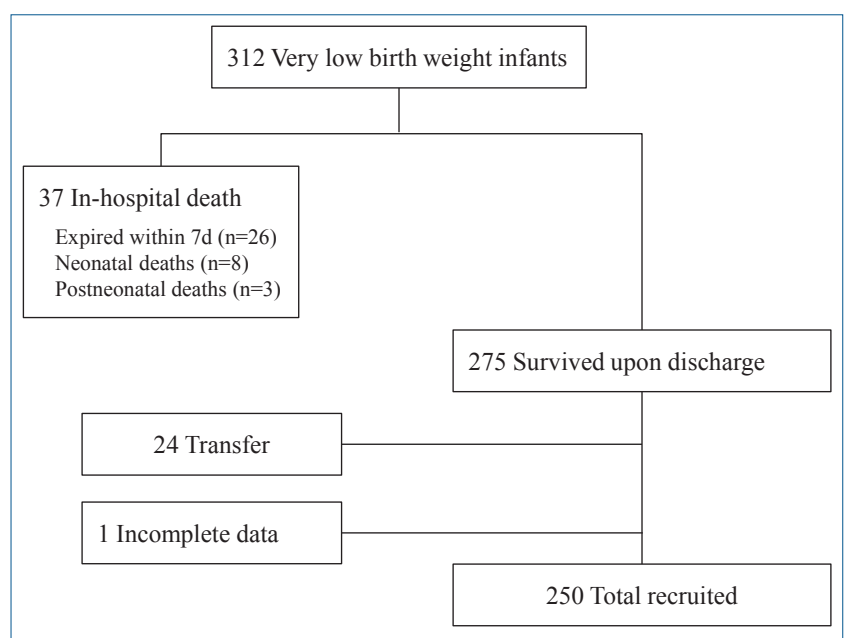

Fig. 1. Flow chart of the study patients. 
ing gestational age, birth weight, sex, small for gestational age, mode of delivery, Apgar scores at 1 and 5 minutes, and multiple gestation.

Maternal history that can affect the fetus was also assessed, including premature rupture of membranes, preeclampsia, gestational diabetes mellitus, and use of antenatal steroids including a single administration.

Neonatal morbidities including the following were documented: respiratory distress syndrome (RDS), BPD, pneumothorax, pulmonary hemorrhage, PDA, early-onset sepsis, late-onset sepsis, NEC (stage $\geq 2$ ), IVH (grade $\geq 1$ ), periventricular leukomalacia (PVL, grade $\geq 1$ ), ROP (stage $\geq 2$ ), duration of hospitalization, and days to reach full feeding.

RDS was diagnosed based on characteristic clinical symptoms and chest X-ray. We defined BPD as patients with persistent oxygen requirement at 36 weeks postmenstrual age. ${ }^{15)}$ Sepsis was diagnosed when positive blood culture and systemic symptoms were present. Early-onset sepsis was defined as sepsis occurring as less than 7 days and late-onset sepsis as sepsis occurring 7 days or more after birth. NEC was diagnosed based on systemic symptoms and radiographic findings, with severity based on modified Bell et al.'s staging criteria. ${ }^{16)}$ PDA was diagnosed by clinical symptoms and echocardiography. ROP was diagnosed by an ophthalmologist following a schedule of the American Academy of Ophthalmology. ${ }^{17)} \mathrm{IVH}$ and PVL were diagnosed by brain ultrasound and brain magnetic resonance imaging (MRI). ${ }^{18-20)}$ Initial brain ultrasound was performed within 72 hours of birth, and rescreening was performed at intervals of 1 to 4 weeks. In cases of abnormal brain ultrasound or neurological symptoms, brain MRI was performed prior to discharge.
In the RBC transfusion group, the number of RBC transfusions, age, and $\mathrm{Hb}$ level at first transfusion were further reviewed.

\section{Statistical analysis}

Data were analyzed using IBM SPSS Statistics ver. 21.0 (IBM Co., Armonk, NY, USA). Data were expressed as number, percentage (\%) for qualitative variables, and mean, standard deviations for quantitative variables. Qualitative variables were compared with the Student $t$ test. Quantitative variables were compared with the $\chi^{2}$ or Fisher exact test. Univariate and multivariate logistic regression analysis was used to evaluate the association between RBC transfusion and neonatal morbidities. A $P$ value of less than 0.05 was considered significant.

\section{Results}

This study enrolled 250 VLBW infants. Among them, 109 infants $(43.6 \%)$ were transfused.

Table 1 describes the patient's demographic features. The median gestational age and birth weight of all patients were 28.8 \pm 2.5 weeks and 1,149.6 $\pm 253.5 \mathrm{~g}$, respectively. Gestational age and birth weight were significantly lower in the transfusion group than in the nontransfusion group $(27.1 \pm 2.0$ weeks and 985.6 $\pm 253.1 \mathrm{~g}$ vs. $30.0 \pm 2.1$ weeks and 1,276.3 $\pm 166.7 \mathrm{~g}$, respectively, $P<0.001)$. There were significant differences in Apgar scores between the groups at both 1 and 5 minutes $(P<0.001)$, and there was a higher incidence of multiple gestation in the nontransfused group $(P=0.032)$.

Morbidities and short-term outcomes are shown in Table 2.

Table 1. Demographic factors of the transfusion and nontransfusion groups

\begin{tabular}{|c|c|c|c|c|}
\hline Variable & Total $(n=250)$ & Transfusion $(n=109)$ & Nontransfusion $(n=141)$ & $P$ value \\
\hline Gestational age (wk) & $28.8 \pm 2.5$ & $27.1 \pm 2.0$ & $30.0 \pm 2.1$ & $<0.001$ \\
\hline Sex & & & & 0.208 \\
\hline Male & $124(49.6)$ & $59(54.1)$ & $65(46.1)$ & \\
\hline Female & $126(50.4)$ & $50(45.9)$ & $76(53.9)$ & \\
\hline Weight (g) & $1,149.6 \pm 253.5$ & $985.6 \pm 253.1$ & $1,276.3 \pm 166.7$ & $<0.001$ \\
\hline SGA & $31(12.4)$ & $9(8.3)$ & $22(15.6)$ & 0.810 \\
\hline Delivery method & & & & 0.818 \\
\hline Vaginal & $33(13.2)$ & $15(13.8)$ & $18(12.8)$ & \\
\hline C-sec & $217(86.8)$ & 94 (86.2) & $123(87.2)$ & \\
\hline \multicolumn{5}{|l|}{ Apgar score } \\
\hline 1 Minute & $5.0 \pm 2.3$ & $4.3 \pm 2.7$ & $5.4 \pm 1.8$ & $<0.001$ \\
\hline 5 Minutes & $7.5 \pm 1.3$ & $6.9 \pm 1.3$ & $8.0 \pm 1.2$ & $<0.001$ \\
\hline Multiple gestation & $55(22.0)$ & $17(15.6)$ & $38(27.0)$ & 0.032 \\
\hline \multicolumn{5}{|l|}{ Mother's disease } \\
\hline PROM & $97(38.8)$ & $48(44.0)$ & $49(34.8)$ & 0.135 \\
\hline Preeclampsia & $60(24.0)$ & $20(18.3)$ & $40(28.4)$ & 0.066 \\
\hline DM & $27(10.8)$ & $11(10.1)$ & $16(11.3)$ & 0.751 \\
\hline ANS & $230(92.0)$ & $103(94.5)$ & $127(90.1)$ & 0.201 \\
\hline
\end{tabular}

Values are presented as mean \pm standard deviation or number (\%).

The $P$ values were calculated by Student $t$ test for continuous variables and the $x^{2}$ test or Fisher exact test for categorical variables.

SGA, small for gestational age; C-sec, cesarean section; PROM, premature rupture of membrane; DM, diabetes mellitus; ANS, antenatal steroids.

Boldface indicates a statistically significant difference with $P<0.05$. 
Table 2. Morbidity and short-term outcomes of the transfusion and nontransfusion groups

\begin{tabular}{|c|c|c|c|c|}
\hline Variable & $\begin{array}{c}\text { Total } \\
(n=250)\end{array}$ & $\begin{array}{l}\text { Transfusion } \\
(n=109)\end{array}$ & $\begin{array}{l}\text { Nontransfusion } \\
\quad(n=141)\end{array}$ & $\begin{array}{c}P \\
\text { value }\end{array}$ \\
\hline RDS & $190(76.0)$ & $101(92.7)$ & $89(63.1)$ & $<0.001$ \\
\hline PDA & & & & $<0.001$ \\
\hline No PDA & $130(52.0)$ & $41(37.6)$ & $89(63.1)$ & \\
\hline Observation & $36(14.4)$ & $11(10.1)$ & $25(17.7)$ & \\
\hline Medication & $60(24.0)$ & $34(31.2)$ & $26(18.4)$ & \\
\hline Operation & $24(9.6)$ & $23(21.1)$ & $1(0.7)$ & \\
\hline BPD & $93(37.2)$ & $79(72.5)$ & $14(9.9)$ & $<0.001$ \\
\hline BPD severity & & & & $<0.001$ \\
\hline Mild & $68(27.2)$ & $58(53.2)$ & $10(7.1)$ & \\
\hline Moderate & $16(6.4)$ & $12(11.0)$ & $4(2.8)$ & \\
\hline Severe & $9(3.6)$ & $9(8.3)$ & $0(0.0)$ & \\
\hline Pneumothorax & $13(5.2)$ & $11(10.1)$ & $2(1.4)$ & 0.002 \\
\hline Pulmonary hemorrhage & $12(4.8)$ & $11(10.1)$ & $1(0.7)$ & 0.001 \\
\hline Sepsis & $37(14.8)$ & $30(27.5)$ & $7(5.0)$ & $<0.001$ \\
\hline Early-onset sepsis & $4(1.6)$ & $4(3.7)$ & $0(0.0)$ & 0.035 \\
\hline Late-onset sepsis & $34(13.6)$ & $26(23.9)$ & $8(5.7)$ & $<0.001$ \\
\hline NEC & $46(18.4)$ & $33(30.3)$ & $13(9.2)$ & $<0.001$ \\
\hline IVH & $40(16.0)$ & $30(27.5)$ & $10(7.1)$ & $<0.001$ \\
\hline PVL & $7(2.8)$ & $5(4.6)$ & $2(1.4)$ & 0.245 \\
\hline ROP & $70(28.0)$ & 54 (49.5) & $16(11.3)$ & $<0.001$ \\
\hline Laser therapy & $28(11.2)$ & $27(24.8)$ & $1(0.7)$ & $<0.001$ \\
\hline Hospital stay (day) & $68.4 \pm 35.4$ & $91.7 \pm 40.7$ & $50.4 \pm 14.3$ & $<0.001$ \\
\hline $\begin{array}{l}\text { Days to reach full feed- } \\
\text { ing (day) }\end{array}$ & $23.0 \pm 28.7$ & $34.0 \pm 39.8$ & $14.5 \pm 8.9$ & $<0.001$ \\
\hline
\end{tabular}

Values are presented as number (\%) or mean \pm standard deviation.

The $P$ values were calculated by Student $t$ test for continuous variables and the $x^{2}$ test or Fisher exact test for categorical variables.

RDS, respiratory distress syndrome; PDA, patent ductus arteriosus; $\mathrm{BPD}$, bronchopulmonary dysplasia; NEC, necrotizing enterocolitis; IVH, intraventricular hemorrhage; PVL, periventricular leukomalacia; ROP, retinopathy of prematurity.

Boldface indicates a statistically significant difference with $P<0.05$.

There were significant associations between RBC transfusions and all short-term outcomes except for PVL. The incidence of RDS, PDA, BPD, pneumothorax, pulmonary hemorrhage, sepsis, NEC, IVH, and ROP, as well as the duration of hospital stay and time to full feeding were significantly higher in the transfusion group than in the nontransfusion group.

Table 3 presents the linear regression analysis performed to determine the effect of RBC transfusion on each disease. Univariate analysis revealed that all short-term outcomes except earlyonset sepsis and PDA were associated with RBC transfusion. RDS, BPD, NEC, IVH, and ROP were selected and multivariate regression analysis was performed, adjusting for gestational age, birth weight and Apgar score at 1 minute. The analysis showed that $\mathrm{RBC}$ transfusion is significantly correlated with $\mathrm{BPD}$ (odds ratio [OR], 5.42; $P<0.001)$ and NEC (OR, 3.40; $P=0.009)$.

In the transfusion group, we compared patients with birth weight less than $1,000 \mathrm{~g}$ to those weighing more than $1,000 \mathrm{~g}$. As shown in Table 4, infants with birth weight $<1,000 \mathrm{~g}$ received $3.1 \pm 2.2$ transfusions, with a first transfusion at $22.1 \pm 16.6$ days. However, infants with birth weight 1,000 to $1,500 \mathrm{~g}$ received only $1.5 \pm 0.8$ transfusions, with a first transfusion at $32.6 \pm 15.2$ days. $\mathrm{RBC}$ transfusions were administered significantly earlier $(P=0.001)$ and more frequently $(P<0.001)$ with smaller birth weight.

\section{Discussion}

RBC transfusion has been known to improve oxygen transport and cardiorespiratory status in preterm infants and has long been used in anemic preterm infants. However, there is now an increasing awareness of the adverse effects of RBC transfusion.

This study is significant in that it reviews data for multiple diseases in $250 \mathrm{VLBW}$ infants from a single hospital NICU in Republic of Korea. Although there has been a report on the causal relationship between RBC transfusion and NEC in Korean NICUs, ${ }^{21)}$ to our knowledge, this is the first study that evaluated the correlation between $\mathrm{RBC}$ transfusion and multiple diseases including IVH, BPD, ROP, NEC, PDA, sepsis.

Many recent studies have demonstrated the association between RBC transfusion and chronic lung disease in premature infants. Damage caused by "oxidative stress" has been presented as a possible causative factor. The serum iron level is increased with the breakdown of heme released from transfused erythrocytes. Iron overload damages tissue by free radicals generated by free iron. Preterm infants are particularly vulnerable to oxidative damage. ${ }^{9}{ }^{910)}$ Similarly, we also confirmed that RBC transfusion was significantly correlated with BPD.

The mechanism of NEC development is unclear, but it is assumed that various risk factors are involved. Recently, the relationship between NEC and RBC transfusion within 48 hours has been reported and is termed as transfusion-related acute gut injury or transfusion-related NEC. ${ }^{6,11,12)}$ An alteration of blood flow associated with feeding, and ischemia/reperfusion associated with RBC transfusion are suggested as a theory. Feeding during $\mathrm{RBC}$ transfusion may increase the risk for mesenteric ischemia and the development of transfusion-related NEC in preterm infants. ${ }^{22}$

In this study, multivariate regression analysis also demonstrated that RBC transfusion was significantly correlated with NEC. We were not able to investigate the association between the time of RBC transfusion and the time of NEC diagnosis. Of 33 patients with both RBC transfusion and NEC diagnosis, 14 were diagnosed with NEC after RBC transfusion, with an interval from 2 days up to 1 month (median, 11.5 days). In addition, due to the absence of a pediatric surgeon in our hospital during the study period, 20 NEC patients requiring surgical intervention were excluded because we were unable to evaluate other morbidities, and 13 of them (65\%) had undergone transfusion before diagnosis. Two additional infants diagnosed with NEC 6 and 11 days after RBC transfusion were also excluded due to death during the hospitalization period.

We found no significant correlation between RBC transfusion and RDS. This may be because RDS is a disease that occurs 
Table 3. Logistic regression analysis of transfusion versus nontransfusion groups

\begin{tabular}{|c|c|c|c|c|}
\hline \multirow{2}{*}{ Variable } & \multicolumn{2}{|c|}{ Univariable } & \multicolumn{2}{|c|}{ Multivariable } \\
\hline & OR $(95 \% \mathrm{Cl})$ & $P$ value & OR $(95 \% \mathrm{Cl})$ & $P$ value \\
\hline Gestational age (wk) & $0.50(0.413-0.595)$ & $<0.001$ & & \\
\hline Weight (g) & 0.99 (0.992-0.995) & $<0.001$ & & \\
\hline \multicolumn{5}{|l|}{ Apgar score } \\
\hline 1 Minute & $0.76(0.665-0.881)$ & $<0.001$ & & \\
\hline 5 Minutes & $0.46(0.349-0.593)$ & $<0.001$ & & \\
\hline RDS & 7.38 (3.324-16.368) & $<0.001$ & $0.79(0.251-2.475)$ & 0.684 \\
\hline \multicolumn{5}{|l|}{ PDA } \\
\hline No PDA & 0.00 (reference) & & & \\
\hline Observation & $0.96(0.429-2.125)$ & 0.910 & & \\
\hline Medication & $2.84(1.511-5.333)$ & 0.001 & & \\
\hline Operation & $49.93(6.518-382.439)$ & $<0.001$ & & \\
\hline BPD & $25.03(12.470-50.218)$ & $<0.001$ & $5.42(2.147-13.685)$ & $<0.001$ \\
\hline Pneumothorax & 7.80 (1.691-35.978) & 0.008 & & \\
\hline Pulmonary hemorrhage & $15.71(1.996-123.705)$ & 0.009 & & \\
\hline \multicolumn{5}{|l|}{ Sepsis } \\
\hline Early-onset sepsis & $<1,000(<0.001$ to $>1,000)$ & 0.999 & & \\
\hline Late-onset sepsis & $5.21(2.252-12.045)$ & $<0.001$ & & \\
\hline NEC & $4.28(2.119-8.625)$ & $<0.001$ & $3.40(1.366-8.460)$ & 0.009 \\
\hline IVH & 4.98 (2.307-10.725) & $<0.001$ & $1.92(0.640-5.736)$ & 0.245 \\
\hline ROP & 7.67 (4.038-14.572) & $<0.001$ & $1.22(0.475-3.142)$ & 0.677 \\
\hline Laser therapy & $46.10(6.149-345.576)$ & $<0.001$ & & \\
\hline Hospital stay (day) & 1.09 (1.070-1.119) & $<0.001$ & & \\
\hline Days to reach full feeding (day) & $1.09(1.062-1.120)$ & $<0.001$ & & \\
\hline
\end{tabular}

$\mathrm{OR}$, odds ratio; $\mathrm{Cl}$, confidence interval; RDS, respiratory distress syndrome; PDA, patent ductus arteriosus; BPD, bronchopulmonary dysplasia; NEC, necrotizing enterocolitis; IVH, intraventricular hemorrhage; ROP, retinopathy of prematurity.

Adjusted variables: gestational age, birth weight, Apgar score at 1 minute.

Boldface indicates a statistically significant difference with $P<0.05$.

Table 4. Transfusions according to birth weight

\begin{tabular}{|c|c|c|c|}
\hline \multirow[b]{2}{*}{ Variable } & \multicolumn{2}{|c|}{ Birth weight } & \multirow[b]{2}{*}{$\begin{array}{c}P \\
\text { value }\end{array}$} \\
\hline & $\begin{array}{c}<1,000 \mathrm{~g} \\
(\mathrm{n}=58)\end{array}$ & $\begin{array}{c}1,000-1,500 \mathrm{~g} \\
(\mathrm{n}=51)\end{array}$ & \\
\hline Hemoglobin at first transfusion (g/dL) & $8.5 \pm 1.4$ & $8.1 \pm 0.9$ & 0.081 \\
\hline Age at first transfusion (day) & $22.1 \pm 16.6$ & $32.6 \pm 15.2$ & 0.001 \\
\hline Number of transfusions & $3.1 \pm 2.2$ & $1.5 \pm 0.8$ & $<0.001$ \\
\hline
\end{tabular}

Values are presented as mean \pm standard deviation.

The $P$ values were calculated by Student $t$ test for continuous variables.

Boldface indicates a statistically significant difference with $P<0.05$.

shortly after birth due to a lack of surfactant and is not related to a short-term complication of RBC transfusion.

We found no significant association between $\mathrm{RBC}$ transfusion and ROP. Recently, correlations with RBC transfusion and iron intake have been reported. ${ }^{23,24)}$ Dani et al. ${ }^{23)}$ reported RBC transfusion is an independent risk factor for the development of ROP, suggesting increased oxygen delivery to the retina and secondary iron overload as mechanisms. However, Brooks at el. ${ }^{5)}$ reported that there was no significant reduction in the incidence of ROP with a more restrictive transfusion policy.

Baer et al. ${ }^{8)}$ and Christensen et al. ${ }^{25)}$ reported the correlation between RBC transfusion and severe IVH. However, in "Premature Infants in Need of Transfusion" study showed no association between IVH and transfusion guideline used. ${ }^{26)}$ In this study, no significant correlation was found between RBC transfusion and IVH. In 30 patients diagnosed with IVH in the transfusion group, 14 patients had diagnosed after RBC transfusions and 2 patients had received RBC transfusions within 1 week of diagnosis.

Preterm infants in the NICU tend to receive more RBC transfusions. According to Korean neonatal network data in 2017, 92.7 $\%$ of infants weighing 700 to $800 \mathrm{~g}$ received RBC transfusions, compared to only $28.6 \%$ of infants weighing 1,400 to 1,500 g. ${ }^{27)}$ Keir et al. ${ }^{28)}$ reported up to $82 \%$ of neonates of the ELBW infants received at least one $\mathrm{RBC}$ transfusion. As frequent blood sampling is done early in life, about $50 \%$ of the ELBW infants receive RBC transfusion within one week of birth. ${ }^{29)}$ We also confirmed that smaller the body weight resulted in earlier and more frequent RBC transfusions.

Due to growing awareness of relationship between RBC transfusion and short-term adverse outcomes, several randomized controlled trials of "liberal" (high Hb threshold) vs "restrictive" (low $\mathrm{Hb}$ threshold) guidelines have been conducted to identify the optimal threshold for RBC transfusion, and guidelines are still controversial. ${ }^{30}$

Setting a low $\mathrm{Hb}$ threshold may be a way to decrease exposure to $\mathrm{RBC}$ transfusion. ${ }^{31)}$ In our hospital, RBC transfusion was based on the guideline as well as the patient's clinical condition. 
However, as awareness of the adverse outcomes of RBC transfusion increased, transfusion rates tended to decrease every year. The RBC transfusion rate of VLBW infants born in 2011 in our NICU was $80 \%$, but it decreased gradually to $63 \%$ in $2012,43 \%$ in 2013 and $26 \%$ in 2017.

It is also important to reduce the number of phlebotomies, because the most common cause of RBC transfusion in VLBW infants is frequent blood samplings. Use of supplemental iron, recombinant EPO, delayed cord clamping, and early aggressive nutritional support are also included to reduce RBC transfusions. $^{32)}$

The limitations of this retrospective review study include the fact that various confounding factors not included in the medical record were not reflected. Because we only reviewed the records before discharge, any outcomes found after discharge may have been missed. As this was a single-institutional study, our RBC transfusion threshold may not correspond with that of other hospitals. We could not accurately assess the relationship between the time of each disease diagnosis and the time of RBC transfusion due to the limitations of medical records.

Nevertheless, this study is remarkable in that it suggests the correlation between RBC transfusion in Korean VLBW infants and adverse clinical outcomes such as NEC and BPD. Appropriate transfusion protocols should be established through evaluation and comparison of RBC transfusion guidelines with other NICUs in Korea. As RBC transfusion may have harmful outcomes as well as beneficial effects, efforts should be made to reduce the number of RBC transfusions and careful consideration of the clinical condition should be required before $\mathrm{RBC}$ transfusion.

\section{Conflicts of interest}

No potential conflict of interest relevant to this article was reported.

\section{Acknowledgments}

This work was supported by the Soonchunhyang University Research Fund.

\section{References}

1. Shim JW, Jin HS, Bae CW. Changes in survival rate for very-low-birthweight infants in Korea: comparison with other countries. J Korean Med Sci 2015;30 Suppl 1:S25-34.

2. Widness JA, Madan A, Grindeanu LA, Zimmerman MB, Wong DK, Stevenson DK. Reduction in red blood cell transfusions among preterm infants: results of a randomized trial with an in-line blood gas and chemistry monitor. Pediatrics 2005;115:1299-306.

3. Widness JA, Seward VJ, Kromer IJ, Burmeister LF, Bell EF, Strauss RG. Changing patterns of red blood cell transfusion in very low birth weight infants. J Pediatr 1996;129:680-7.

4. Baer VL, Lambert DK, Henry E, Snow GL, Christensen RD. Red blood cell transfusion of preterm neonates with a Grade 1 intraventricular hemorrhage is associated with extension to a Grade 3 or 4 hemorrhage. Transfusion 2011;51:1933-9.

5. Brooks SE, Marcus DM, Gillis D, Pirie E, Johnson MH, Bhatia J. The effect of blood transfusion protocol on retinopathy of prematurity: A prospective, randomized study. Pediatrics 1999;104(3 Pt 1):514-8.

6. Mohamed A, Shah PS. Transfusion associated necrotizing enterocolitis: a meta-analysis of observational data. Pediatrics 2012;129:529-40.

7. Zhang Z, Huang X, Lu H. Association between red blood cell transfusion and bronchopulmonary dysplasia in preterm infants. Sci Rep 2014;4: 4340.

8. Baer VL, Lambert DK, Henry E, Snow GL, Butler A, Christensen RD. Among very-low-birth-weight neonates is red blood cell transfusion an independent risk factor for subsequently developing a severe intraventricular hemorrhage? Transfusion 2011;51:1170-8.

9. Hirano K, Morinobu T, Kim H, Hiroi M, Ban R, Ogawa S, et al. Blood transfusion increases radical promoting non-transferrin bound iron in preterm infants. Arch Dis Child Fetal Neonatal Ed 2001;84:F188-93.

10. Collard KJ. Is there a causal relationship between the receipt of blood transfusions and the development of chronic lung disease of prematurity? Med Hypotheses 2006;66:355-64.

11. Blau J, Calo JM, Dozor D, Sutton M, Alpan G, La Gamma EF. Transfusion-related acute gut injury: necrotizing enterocolitis in very low birth weight neonates after packed red blood cell transfusion. J Pediatr 2011; 158:403-9.

12. Paul DA, Mackley A, Novitsky A, Zhao Y, Brooks A, Locke RG. Increased odds of necrotizing enterocolitis after transfusion of red blood cells in premature infants. Pediatrics 2011;127:635-41.

13. Korean Society of Neonatology. Manual of neonatal care. 3rd ed. Seoul (Korea): Korean Society of Neonatology, 2014.

14. Fasano RM, Said M, Luban NL. Blood component therapy for the neonate. In: Martin RJ, Fanaroff AA, Walsh MC, editors. Fanaroff and Martin's neonatal-perinatal medicine: Diseases of the fetus and infant. 10th ed. Philadelphia (PA): Elsevier Saunders, 2015:1344-61.

15. Jobe AH, Bancalari E. Bronchopulmonary dysplasia. Am J Respir Crit Care Med 2001;163:1723-9.

16. Bell MJ, Ternberg JL, Feigin RD, Keating JP, Marshall R, Barton L, et al. Neonatal necrotizing enterocolitis. Therapeutic decisions based upon clinical staging. Ann Surg 1978;187:1-7.

17. Fierson WM; American Academy of Pediatrics Section on Ophthalmology; American Academy of Ophthalmology; American Association for Pediatric Ophthalmology and Strabismus; American Association of Certified Orthoptists. Screening examination of premature infants for retinopathy of prematurity. Pediatrics 2018;142:e20183061.

18. Benson JE, Bishop MR, Cohen HL. Intracranial neonatal neurosonography: an update. Ultrasound Q 2002;18:89-114.

19. Flodmark O, Roland EH, Hill A, Whitfield MF. Periventricular leukomalacia: radiologic diagnosis. Radiology 1987;162(1 Pt 1):119-24.

20. Dorner RA, Burton VJ, Allen MC, Robinson S, Soares BP. Preterm neuroimaging and neurodevelopmental outcome: a focus on intraventricular hemorrhage, post-hemorrhagic hydrocephalus, and associated brain injury. J Perinatol 2018;38:1431-43.

21. Bak SY, Lee S, Park JH, Park KH, Jeon JH. Analysis of the association between necrotizing enterocolitis and transfusion of red blood cell in very low birth weight preterm infants. Korean J Pediatr 2013;56:112-5.

22. Marin T, Josephson CD, Kosmetatos N, Higgins M, Moore JE. Feeding preterm infants during red blood cell transfusion is associated with a decline in postprandial mesenteric oxygenation. J Pediatr 2014;165:46471.

23. Dani C, Reali MF, Bertini G, Martelli E, Pezzati M, Rubaltelli FF. The role of blood transfusions and iron intake on retinopathy of prematurity. Early Hum Dev 2001;62:57-63.

24. Wang YC, Chan OW, Chiang MC, Yang PH, Chu SM, Hsu JF, et al. Red blood cell transfusion and clinical outcomes in extremely low birth weight preterm infants. Pediatr Neonatol 2017;58:216-22.

25. Christensen RD, Baer VL, Lambert DK, Ilstrup SJ, Eggert LD, Henry E. Association, among very-low-birthweight neonates, between red 
blood cell transfusions in the week after birth and severe intraventricular hemorrhage. Transfusion 2014;54:104-8.

26. Kirpalani H, Whyte RK, Andersen C, Asztalos EV, Heddle N, Blajchman MA, et al. The Premature Infants in Need of Transfusion (PINT) study: a randomized, controlled trial of a restrictive (low) versus liberal (high) transfusion threshold for extremely low birth weight infants. J Pediatr 2006;149:301-7.

27. The Executive Committee of Korean Neonatal Networt. 2015 Korean neonatal network annual report. Cheongju (Korea): Korean Centers for Disease Control and Prevention, 2016.

28. Keir AK, Yang J, Harrison A, Pelausa E, Shah PS; Canadian Neonatal Network. Temporal changes in blood product usage in preterm neonates born at less than 30 weeks' gestation in Canada. Transfusion 2015;55: 1340-6.
29. Ohls RK. Why, when and how should we provide red cell transfusions to neonates? In: Polin RA, editor. Hematology, immunology and infectious disease: neonatology questions and controversies. Philadelphia (PA): Saunders, 2008:44-57.

30. Howarth C, Banerjee J, Aladangady N. Red blood cell transfusion in preterm infants: current evidence and controversies. Neonatology 2018; 114:7-16.

31. Heeger LE, Counsilman CE, Bekker V, Bergman KA, Zwaginga JJ, Te Pas $\mathrm{AB}$, et al. Restrictive guideline for red blood cell transfusions in preterm neonates: effect of a protocol change. Vox Sang 2019;114:57-62.

32. Christensen RD, Ilstrup S. Recent advances toward defining the benefits and risks of erythrocyte transfusions in neonates. Arch Dis Child Fetal Neonatal Ed 2013;98:F365-72. 